\title{
Article
}

\section{Adsorption Behavior of Carnosine and Anserine on Copper (II) Immobilized Cation Exchange Resins}

\author{
*Tatsuya Oshima, Kenzo Kanemaru, Kaoru Ohe, and Yoshinari Baba \\ Department of Applied Chemistry, Faculty of Engineering, University of Miyazaki, 1-1, Gakuen Kibanadai Nishi, \\ Miyazaki, 889-2192, Japan
}

(Manuscript submitted March 29, 2007 ; accepted May 23, 2007)

\begin{abstract}
Adsorption behaviors of the histidine-containing dipeptides, carnosine (Car) and anserine (Ans) were studied using copper(II) immobilized cation exchange resins. Commercial sulfonic acid, carboxylic acid, iminodiacetic acid (IDA), and aminophosphoric acid resins were used for immobilizing copper(II). Adsorptions of Car and Ans were especially enhanced using copper(II) immobilized IDA resin (Cu-IDA). Car and Ans were adsorbed on $\mathrm{Cu}$-IDA even in the presence of $100 \mathrm{mmol} / \mathrm{dm}^{3}$ of sodium chloride. Histidine and the histidine-containing dipeptides were selectively adsorbed on Cu-IDA over other amino acids. Immobilized metal affinity adsorption is available for separation of the dipeptides from saline water.
\end{abstract}

Key words: IMAC(Immobilized metal affinity chromatography), carnosine, anserine, adsorption, separation

\section{Introduction}

Naturally-occurring histidine-containing dipeptides, carnosine (Car, $\beta$-alanyl-L-histidine) and anserine (Ans, $\beta$-alanyl-L-1-methylhistidine) (shown in Fig. 1), are believed to act as cytosolic buffering agents, metal ion chelators, anti-oxidants, and to have neurotransmitter functions [1-3]. As such, they are used as raw materials for food supplements. Food extracts and food wastes might be candidates to cheaply recover histidine-containing dipeptides; however, this source would contain also other amino acids and inorganic salts.

Ion exchange techniques are effective for separation of amino acids and peptides; however, adsorption on ion exchange resins significantly decreases in saline water because of the inhibition of adsorption by salts such as $\mathrm{NaCl}$. In the present study, the adsorptions of histidine-containing dipeptides using immobilized metal affinity adsorption were studied. Immobilized metal affinity chromatography (IMAC) has been developed as a selective separation tool for biomolecules [4-9]. The separation factor of IMAC is based on differences in the affinities between immobilized metal ions and functional groups of biomolecules. Immobilized intermediate metal ions such as $\mathrm{Cu}(\mathrm{II}), \mathrm{Ni}(\mathrm{II})$, and $\mathrm{Zn}(\mathrm{II})$ bind proteins with histidine residues.

Especially, IMAC is used for the purification of recombinant proteins. Recombinant proteins fusing peptide tags containing multiple histidines to their $\mathrm{C}$ - or $\mathrm{N}$-terminus are selectively adsorbed on metal immobilized chelating gels. $\mathrm{Cu}(\mathrm{II})$ immobilized cation exchange resins were prepared from commercial sulfonic acid, carboxylic acid, iminodiacetic acid, and aminophosphoric acid resins for the recovery of Car and Ans

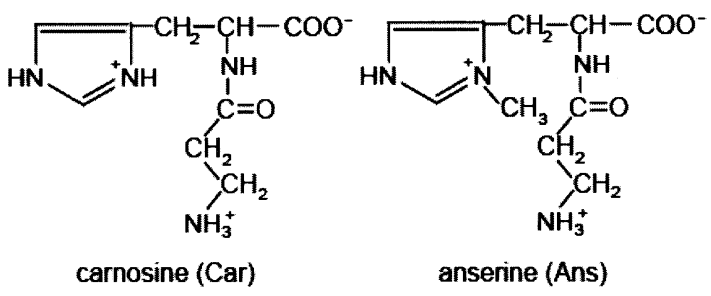

Fig. 1 Molecular structures of Car and Ans 
from saline water. The metal immobilized resins were expected to adsorb the peptides with less interference from any coexisting inorganic ions. They would also possess selectivity for the histidine-containing dipeptides over other amino acids.

\section{Experimental}

\subsection{Materials}

Figure 2 shows the molecular structures of the cation exchange resins used in this study. DIAION ${ }^{\circledR}$ SK-1B (abbreviated as SK), WK10 (WK), and CR11 (IDA) were kindly supplied by Mitsubishi Chemical Co., Japan. LEWATIT ${ }^{\circledR}$ TP260 (TP) was kindly supplied by LANXESS K.K., Japan. The cationic resins were washed with $0.1 \mathrm{~mol} / \mathrm{dm}^{3}$ of $\mathrm{NaOH}, 0.3 \mathrm{~mol} / \mathrm{dm}^{3}$ of $\mathrm{HCl}, 0.3 \mathrm{~mol} / \mathrm{dm}^{3}$ of $\mathrm{NaCl}$, and finally distilled water.

Analytical grade amino acid reagents for the adsorption experiments were purchased and employed without further purification: i.e., L-carnosine (Car), L-anserine (Ans), (Sigma-Aldrich Co., USA), L-glutamic acid (Glu), glycine (Gly), L-cysteine (Cys), L-methionine (Met), L-tryptophan (Trp), L-phenylalanine (Phe), L-histidine (His), and L-arginine (Arg) (Wako Pure Chemical Industries, Japan). All other reagents were of reagent grade and were used as received.

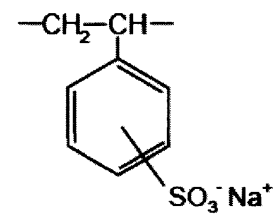

DIAION SK1B (SK)

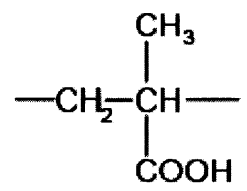

DIAION WK10 (WK)

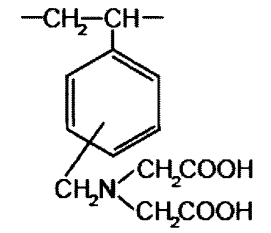

DIAION CR11 (IDA)

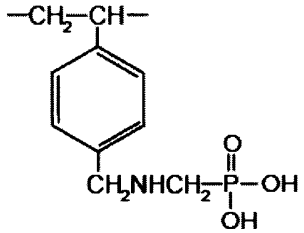

LEWATIT TP260 (TP)

Fig. 2 Molecular structures of cation exchange resins used in this study

\subsection{Preparation of Copper(II) Immobilized Resins}

$\mathrm{Cu}$-IDA was prepared by $\mathrm{Cu}(\mathrm{II})$ ion adsorption on IDA as follows: An aqueous solution containing 10.0 $\mathrm{mmol} / \mathrm{dm}^{3}$ of $\mathrm{Cu}\left(\mathrm{NO}_{3}\right)_{2}$ was prepared and the $\mathrm{pH}$ was adjusted to $4.3 \mathrm{using} 5.0 \mathrm{mmol} / \mathrm{dm}^{3}$ of HEPES buffer and diluted hydrochloric acid. A $1.0 \mathrm{dm}^{3}$ portion of the aqueous solution and $5.0 \mathrm{~g}$ of IDA were mixed in a beaker and then stirred $(150 \mathrm{rpm})$ at R.T. After $20 \mathrm{~h}$, the adsorption reached equilibrium and the mixture was filtrated to collect the resin. The concentrations of $\mathrm{Cu}(\mathrm{II})$ in the remaining filtrate were analyzed using an atomic absorption spectrophotometer (PerkinElmer AAnalyst 100) to determine the amount of metal adsorbed. Cu(II) immobilized resins $\mathrm{Cu}-\mathrm{SK}, \mathrm{Cu}-\mathrm{WK}$, and $\mathrm{Cu}-\mathrm{TP}$ were prepared in a similar manner, using $\mathrm{SK}$, WK, and TP resins at $\mathrm{pH} 4.3$ for SK and TP or pH6.0 for WK.

\subsection{Adsorption Tests}

An aqueous solution containing $0.25 \mathrm{mmol} / \mathrm{dm}^{3}$ of Car was prepared and the $\mathrm{pH}$ adjusted using 10.0 $\mathrm{mmol} / \mathrm{dm}^{3}$ of HEPES buffer, diluted hydrochloric acid, and diluted sodium hydroxide. $15 \mathrm{~cm}^{3}$ of the aqueous solution and $30 \mathrm{mg}$ of a resin were mixed in a stoppered Erlenmeyer flask and shaken in a thermostated shaker $(130 \mathrm{rpm})$ at $30^{\circ} \mathrm{C}$. After $20 \mathrm{~h}$, the adsorption reached an equilibrium state and the mixture was filtrated to obtain the filtrate. To determine the percent adsorption of Car, the concentrations of Car in the aqueous solutions were analyzed using a Shimadzu Prominence HPLC Amino Acid Analysis System based on post-column fluorescence detection. The concentrations of $\mathrm{Cu}(\mathrm{II})$ ions eluted from $\mathrm{Cu}$-IDA resin were also analyzed using an atomic absorption spectrophotometer.

\section{Results and Discussion}




\subsection{Adsorption Behavior of Carnosine}

The amounts of $\mathrm{Cu}(\mathrm{II})$ immobilized on resins by the adsorption procedure were $1.52 \mathrm{mmol} / \mathrm{g}$ for $\mathrm{Cu}-\mathrm{SK}$, $1.43 \mathrm{mmol} / \mathrm{g}$ for $\mathrm{Cu}-\mathrm{WK}, 1.36 \mathrm{mmol} / \mathrm{g}$ for $\mathrm{Cu}-\mathrm{IDA}$, and $1.96 \mathrm{mmol} / \mathrm{g}$ for $\mathrm{Cu}-\mathrm{TP}$. The amounts of adsorption are smaller than those of the maximum adsorption capacities of the resins. Adsorption of Car on the original resins and on the $\mathrm{Cu}(\mathrm{II})$ immobilizing resins were carried out under various pHs and the results are shown in Figs. 3-6.

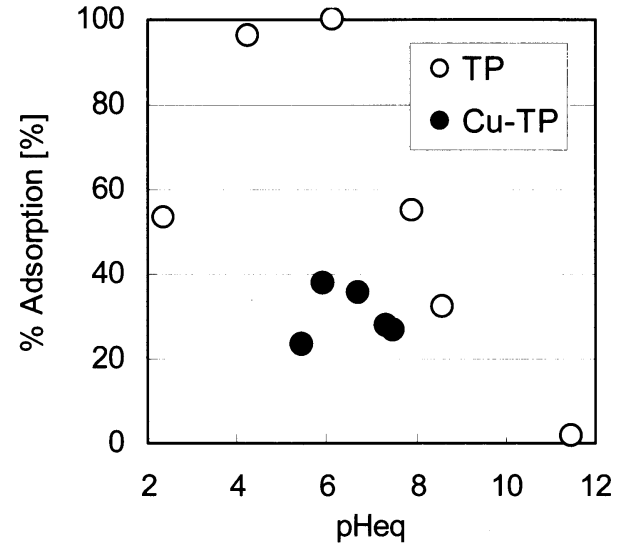

Fig. 3 Adsorption profiles of Car on TP and $\mathrm{Cu}$-TP. Adsorbent, $30 \mathrm{mg}$; Volume $=15 \mathrm{~cm}^{3}$; $[\text { Car }]_{\text {ini }}=2.5 \times 10^{-4} \mathrm{~mol} / \mathrm{dm}^{3}$.

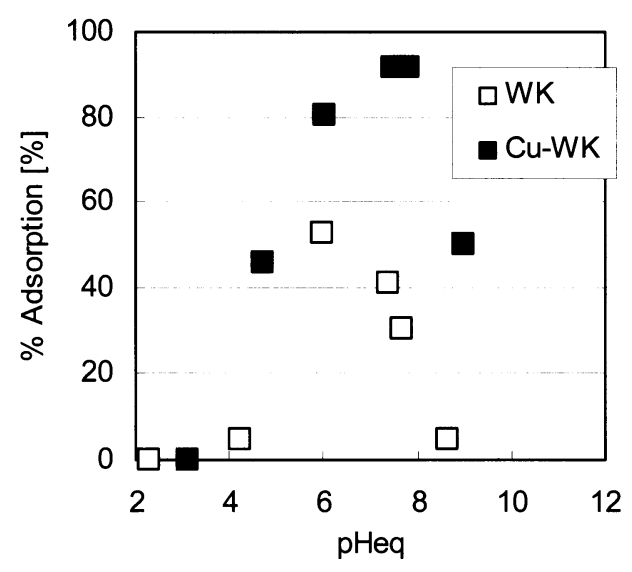

Fig. 5 Adsorption profiles of Car on WK and $\mathrm{Cu}-\mathrm{WK}$. Adsorbent, $30 \mathrm{mg}$; Volume $=15 \mathrm{~cm}^{3}$; $[\mathrm{Car}]_{\mathrm{ini}}=2.5 \times 10^{-4} \mathrm{~mol} / \mathrm{dm}^{3}$.

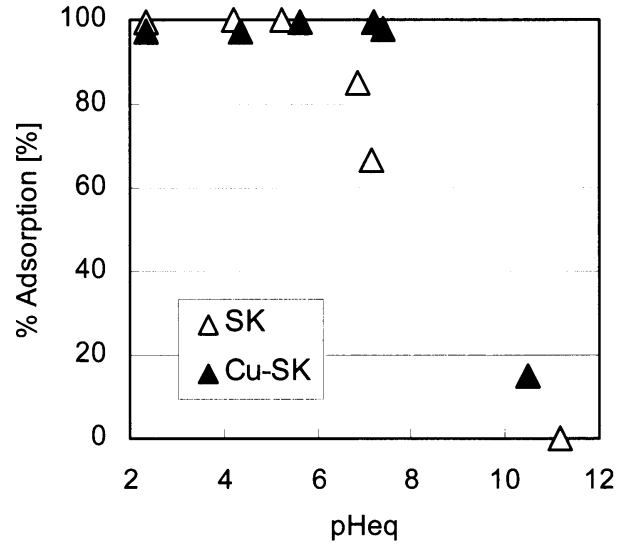

Fig. 4 Adsorption profiles of Car on SK and $\mathrm{Cu}-\mathrm{SK}$. Adsorbent, $30 \mathrm{mg}$; Volume $=15 \mathrm{~cm}^{3}$; $[\mathrm{Car}]_{\mathrm{ini}}=2.5 \times 10^{-4} \mathrm{~mol} / \mathrm{dm}^{3}$.

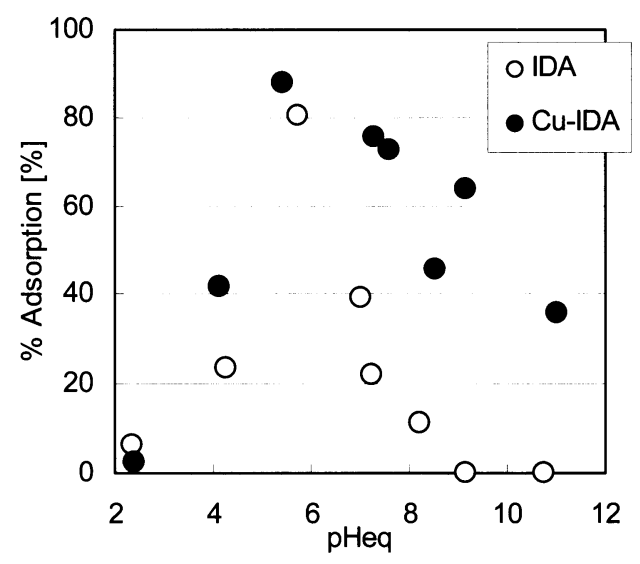

Fig. 6 Adsorption profiles of Car on IDA and $\mathrm{Cu}$-IDA. Adsorbent, $30 \mathrm{mg}$; Volume $=15 \mathrm{~cm}^{3}$; $[\mathrm{Car}]_{\mathrm{ini}}=2.5 \times 10^{-4} \mathrm{~mol} / \mathrm{dm}^{3}$.

An aminophosphoric acid resin TP exhibits the high adsorption of Car under pH 4-6; however, the adsorption of Car decreases using the metal immobilized resin $\mathrm{Cu}$-TP. $\mathrm{As} \mathrm{Cu}(\mathrm{II})$ ions seem to be competitive with the peptides for adsorption on TP. Thus, TP is inadequate as a material for metal affinity adsorption of the histidine-containing peptides. A strong acid ion-exchange resin SK quantitatively adsorbs Car under $\mathrm{pH} 2-5$, and the adsorption decreases under higher $\mathrm{pH}$. $\mathrm{Cu}$-SK shows slightly higher adsorption than $\mathrm{SK}$ under neutral $\mathrm{pH}$. Most Car seems to be adsorbed on Cu-SK through electrostatic interaction, while a small amount of Car appears to be adsorbed on it through metal-ligand interaction.

On the other hand, $\mathrm{Cu}-\mathrm{WK}$ and $\mathrm{Cu}$-IDA show higher adsorption of Car than WK and IDA, respectively. Adsorptions of $\mathrm{Car}$ on $\mathrm{Cu}-\mathrm{WK}$ and $\mathrm{Cu}-\mathrm{IDA}$ under neutral $\mathrm{pH}$ are doubled against that on WK and IDA, respectively. Additionally, $\mathrm{Cu}$-IDA can adsorb Car under basic conditions in which IDA cannot adsorb at all. 
Under such basic conditions, Car exists as anionic species and is adsorbed on the Cu-IDA only coordination bond between $\mathrm{Cu}$ (II) ion and $\mathrm{Car}$. $\mathrm{Cu}$ (II) ions immobilized on $\mathrm{Cu}$-IDA were not eluted at all during the adsorption of $\mathrm{Car}$ under a neutral $\mathrm{pH}$. Moreover, the amount of elution of $\mathrm{Cu}$ (II) ions from $\mathrm{Cu}$-IDA under acidic conditions was smaller than those from $\mathrm{Cu}-\mathrm{TP}, \mathrm{Cu}-\mathrm{SK}$, and $\mathrm{Cu}-\mathrm{WK}$ (data not shown). The results show that $\mathrm{Cu}-\mathrm{IDA}$ is a desirable adsorbent for histidine-containing dipeptides by immobilized metal affinity adsorption. The iminodiacetic acid group is one of the most commonly used chelating groups for IMAC.

\subsection{Adsorption selectivity of amino acids on Cu-IDA}

Adsorptions of various amino acids on $\mathrm{Cu}$-IDA were individually examined under a neutral $\mathrm{pH}$ in the absence or presence of $\mathrm{NaCl}$ (Fig. 7). His and the histidine-containing dipeptides, $\mathrm{Car}$ and Ans were selectively adsorbed on $\mathrm{Cu}$-IDA over other amino acids. As the adsorption is mainly based on a coordination bond between metal ions and amino acid, His, which forms the strong complex with $\mathrm{Cu}(\mathrm{II})$ ions, showed the highest adsorption $[7,8]$.

It should be noted that His, Car, and Ans were adsorbed on $\mathrm{Cu}$-IDA in the presence of $100 \mathrm{mmol} / \mathrm{dm}^{3}$ of $\mathrm{NaCl}$. The metal affinity adsorption functions for recovering the histidine-containing peptides from saline solution, for which general ion exchange resins do not [9]. Adsorption of Arg on $\mathrm{Cu}$-IDA was decreased from

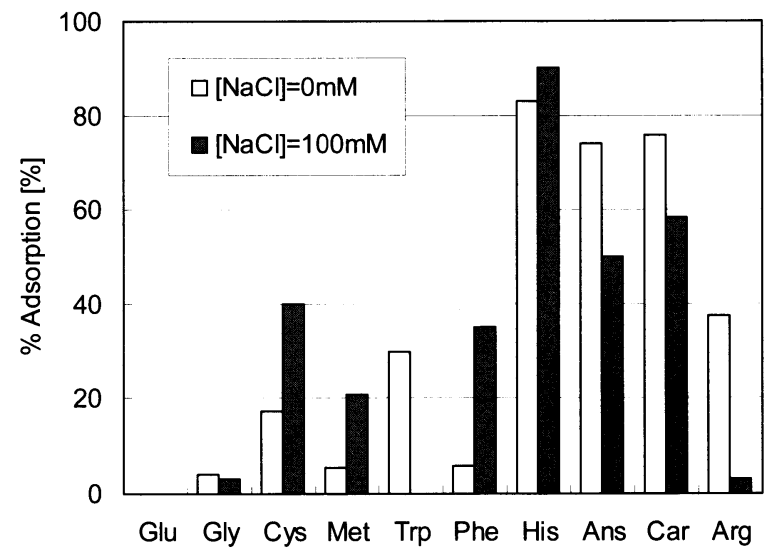

Fig. 7 Adsorptions of amino acids on $\mathrm{Cu}-\mathrm{IDA}$ : $\mathrm{pH}_{\mathrm{eq}}$ 7.0-7.4, Adsorbent, $30 \mathrm{mg}$; Volume $=15 \mathrm{~cm}^{3}$; [amino acid $]_{\text {ini }}=2.5 \times 10^{-4} \quad \mathrm{~mol} / \mathrm{dm}^{3}, \quad[\mathrm{NaCl}]=0$ or $\quad 100$ $\mathrm{mmol} / \mathrm{dm}^{3}$. $37 \%$ to $3 \%$ by adding $100 \mathrm{mmol} / \mathrm{dm}^{3}$ of $\mathrm{NaCl}$, because the basic amino acid Arg is adsorbed mainly by electrostatic interaction. On the other hand, adsorptions of Cys, Met and Phe were increased by adding $\mathrm{NaCl}$. These also seemed to be adsorbed on $\mathrm{Cu}$-IDA through metal-ligand interactions.

In conclusion, immobilized metal affinity adsorption is available for the separation of physiologically important histidine-containing dipeptides from saline solutions containing other amino acids, without going through a desalination process. Commercial iminodiacetic acid resins can be used as the matrix for this metal affinity adsorption. Recovery of dipeptides from $\mathrm{Cu}(\mathrm{II})$ immobilized cations is now under way.

\section{Acknowledgement}

This study was supported by a cooperation grant for innovative technology and advanced research in evolutional areas from Ministry of Education, Science, Sports and Culture of Japan.

\section{References}

1) A. A. Boldyrev, and S. E. Severin, $A d v$. Enzyme Regul., 30, 175-188 (1990).

2) R. Kohen, Y. Yamamoto, K. Cundy, and B. Ames, Proc. Natl. Acad. Sci. USA, 85, 3175-3179 (1988).

3) F. L. Margolis, Science, 184, 909-911 (1974).

4) J. Porath, J. Carlsson, I. Olsson, and G. Belfrage, Nature, 258, 598-599 (1975).

5) J. Porath, Protein Expr. Purif, 3, 263-281 (1992).

6) G. S. Chaga, J. Biochem. Biophys. Methods, 49, 313-334 (2001).

7) Z. E. Rassi, and C. Horváth, J. Chromatogr., 359, 241-253 (1986).

8) E. S. Hemdan, and J. Porath, J. Chromatogr., 323, 255-264 (1985).

9) G. Chaga, J. Porath, and T. Illéni, Biomed. Chromatogr., 7, 256-261 (1993). 